\title{
Investigating signs and symptoms in dry eyed patients
}

Any attempt at the categorisation of patients suffering from dry eyes presents the investigator with a complex problem, constantly evolving in the light of new discoveries.

Primary and secondary Sjögren's syndrome and the rarer Sjögren's syndrome in childhood, certainly show features of generalised disease distinctive from each other. Primary Sjögren's syndrome describes a range of patients who may suffer predominantly from surface exocrine disease - for example, involving the eyes, mouth, or genital tract, or internal exocrine disease affecting the lung parenchyma hepatobiliary system, or pancreas. ${ }^{1-6}$ Secondary Sjögren's syndrome victims, in general, present with rheumatoid arthritis or another connective tissue disorder such as systemic lupus erythematosus or dermatomyositis. ${ }^{2}$ These two conditions although sharing many clinical and laboratory features are also distinguishable from each other in that they display different ranges of autoantibodies, ${ }^{3-5}$ genetic predisposition, ${ }^{5-9}$ possible reaction to viruses such the Epstein-Barr virus, ${ }^{8}{ }^{10-12}$ and retroviruses. ${ }^{13} 14$

Keratoconjunctivitis sicca also develops in older age groups, particularly in those over the age of 80 and has also been recognised in various middle aged patients suffering from Hashimoto's thyroiditis, primary biliary cirrhosis, ${ }^{15}$ or in those with no discernible clinical or laboratory disorder.

Three 'ocular' areas are at risk in dry eyed patients - the lacrimal gland, the conjunctiva, and the cornea. Pathology of the lacrimal gland in both primary and secondary Sjögren's syndrome is identical and well documented, from the time of Sjögren's original description to more recent studies of biopsies and postmortem material. ${ }^{16}$ How the inflammatory reaction is set off, of course, remains problematical but in the worst scenario, the gland is replaced with fibrotic tissue following on periods of prolonged massive focal inflammatory infiltration. In the dry eyes of 'old age' fibrotic replacement gradually develops without dramatic massive inflammatory episodes. Some studies, however, indicate that throughout a lifetime the lacrimal gland may suffer from focal areas of perivascular inflammation leading to pockets of fibrosis. ${ }^{17}$ In short, there is more than one way to end up with a nonproductive lacrimal gland.

To add to the complexity of the situation, the conjunctival epithelial changes in both primary and secondary Sjögren's syndrome are quite distinctive in that they show stratification of the conjunctival epithelium with a progressive loss of nuclei, fragility of the epithelial surface, as shown in the form of a tendency for separation, and a progressive goblet cell deterioration and loss. In contrast, the dry eye of old age shows patchy atrophy and hyperplasia of the conjunctiva but no sign of stratification though, in common with patients with Sjögren's syndrome, the goblet cells gradually disappear. ${ }^{18} 19$ The reasons for conjunctival epithelial dysfunction in these two forms of keratoconjunctivitis sicca, must then be quite different.

In the majority of patients suffering from keratoconjunctivitis sicca, there is no clinical evidence of corneal epithelial involvement. Seventy five per cent of patients show conjunctival interpalpable staining only. However, with a disrupted tear film and a faster than average tear break up time, the corneal surface is at risk.

What can an ophthalmologist hope to contribute in such a complex situation?

Clinical accuracy and diagnosis, provision of samples of tears and tissues for laboratory examination, and careful assessment of changes in signs and symptoms resulting from therapy are all areas in which the interested and committed clinician can participate.

In this month's issue of the BfO (p 533), Yokoi et al present the results of applying hyaluronan to the corneal surface of 11 dry eyed patients, seven of whom had Sjögren's syndrome. In all 11 of their cases dysfunction of the corneal epithelial barrier was recognised by using fluorophotometry. After 2 weeks, hyaluronan treated right corneas showed significant corneal epithelial barrier improvement in the lower portion and after 4 weeks the central cornea also improved. The left corneas treated only with artificial tears showed no improvement at all. The authors conclude that hyaluronan is effective in the treatment of corneal epithelial disruption in the dry eye. The beauty of this concise and uncomplicated paper is the way in which the authors don't try to answer too many questions at one time. Their claims are modest and indeed they refer to previous studies offering indifferent results, particularly from the patient's viewpoint on the use of this substance as a standard therapy.

In the complicated multiaetiological world of dry eyes, diagnostic problems and phases of activity can play havoc with clinical trials. Yokoi et al, in this study, concentrated on specific signs only. Whether hyaluronan will prove to be an effective treatment, reducing both symptoms and signs, remains to be seen.

J WILLIAMSON

Southern General Hospital NHS Trust,

1345 Govan Road, Glasgow G51 4TF

Oxholm P, Asmussen K. Primary Sjogren's syndrome: the challenge for classification of disease manifestations. F Intern Med 1996;239:467-74.

Manthorpe R, Jacobsson LT. Sjogren's syndrome. Baillière's Clin Rheumatol 1995;9:483-96.

3 Oxholm P. Primary Sjogren's syndrome: clinical and laboratory markers of disease activity. Semin Arthritis Rheum 1992;22:114-26.

4 Smeenk RJ. Ro/SS-A and La/SS-B: autoantigens in Sjogren's syndrome? Clin Rheumatol 1995;14 (Suppl 1):11-6.

5 Price EJ, Venables PJ. The etiopathogenisis of Sjogren's syndrome. Semin Arthritis Rheum 1995;25:117-33.

6 Anaya JM, Ogawa N, Talal N. Sjogren's syndrome in childhood. F Rheumatol 1995;22:1152-8.

7 Matsumoto I, Tsubota K, Satake Y, Kita Y, Matsumura R, Murata H, et al. Common T cell receptor clonotype in lacrimal glands and labial salivary glands from patients with Sjogren's syndrome. F Clin Invest 1996;97:196977

8 Pflugfelder SC, Crouse CA, Monroy D, Yen M, Rowe M, Atherton SS. Epstein-Barr virus and the lacrimal gland pathology of Sjogren's syndrome. Am f Pathol 1993;143:49-64.

9 Fox RH, Khang HI. Pathogenisis of Sjogren's syndrome rheumatic diseases. Clin N Am 1992;18:517-38.

10 Pflugfelder SC, Tseng SC, Peposej S, Fletcher MA, Klimas N,Wfeuer W. Epstein-Barr virus infection and immunologic dysfunction in patient's with aqueous tear deficiency. Ophthalmology 1990;97:313-23.

11 Fox RI, Chilton T, Scott S, Benton L Howell FV, Vaughan JH. Potential role of Epstein-Barr virus in Sjogren's syndrome. Rheum Dis Clin N Am 1987; 13:275-92.

12 Tsubota K, Fujushima H, Toda I, Katagiri S, Kawashima, Y Saito I. Increased levels of Epstein-Barr virus DNA in the lacrimal glands of Sjogren's syndrome patients. Acta Ophthalmol Scand 1995;73:425-30.

13 Suzuki K, Makino M, Okada Y, Kinoshito J, Yui R, Kanazawa H, et al. Exocrinopathy resembling Sjogren's syndrome induced by a murine retrovirus. Lab Invest 1993;69:430-5.

14 Talal N. Immunologic and viral factors in Sjogren's syndrome. Clin Exp Rheumatol 1990;8 (Suppl 5):23-6.

15 Williamson J, Louden Brown R. The eye and connective tissue disease. London: Edward Arnold, 1978: Chapter I-1.

16 Williamson J, Gibson AAM, Wilson T. Histology of the lacrimal gland in keratoconjunctivitis sicca. Br f Ophthalmol 1973;57:852-8.

17 Segerberg-Conttinen $M$. A post mortem study of focal andenitis in the salivary and lacrimal glands. F Auto-immun 1989;2:553-8.

18 Abdel-Khalek LMR, Williamson J, Lee WR. Morphological changes in the human conjunctival epithelium. 1 In the normal elderly population. $\mathrm{Br} \mathcal{F}$ human conjunctival epithel

19 Abdel-Khalek LMR, Williamson J, Lee WR. Morphological changes in human conjunctival epithelium. 2 In keratoconjunctivitis sicca. $\mathrm{Br} f$ Ophthalmol 1978;62:800-6. 